\title{
Disabled People Marriage; an Overview for Different Perspectives
}

\author{
Dr. Noor Talal AL Bdour and Dr. Fasial Mohammad AL Shogirat
}

\begin{abstract}
The present study aimed at reviewing the attitudes on the issue of disabled persons marriage from different points of view as society, families, individuals with disabilities and law according to different variables. In general, attitudes towards marriage of disabled persons were negative with an inverse relationship between attitudes of families towards marriage of their children with disabilities and quality of life.

Points of view differed according to type of disability too, most attitudes towards marriage of persons with mild intellectual disabilities tended to be rejected, while marriage attitudes towards persons with physical or sensory (visual and hearing) disabilities were better in terms of sexual relations, marriage and childbearing than individuals with intellectual disability.

law recognizes marriage right for persons with disabilities if it approves person's with disabilities benefits, under an official medical report and within special conditions. The study concluded with a set of recommendation.
\end{abstract}

Keywords — Disabled People, Marriage, Perspectives.

\section{INTRODUCTION}

Marriage issue of persons with disabilities is an important issue in the field of special education, especially in the light of increasing the awareness among various societies of the importance of improving the good life quality and decent living for them, this accompanied with the emergence of many legislations and laws that guarantee their rights in economic , social life aspects. One of the most important social rights of disabled person is his right in marriage; to satisfy his sexual needs and have children like ordinary people. Here, we find a contradictory view from those who interested in this field, families and individuals with disabilities.

One team conformed that right and believed in the fact that Disabled Person are human being and their biological composition and innate abilities require sexual relationship and most of them have desire to form families and have children, and they also achieve social and psychological balance and alleviates depression and loneliness

Other team opposed and rejected idea of disabled persons marriage, judged in advance on expected failure, considered it as a failed experience, and view their marriage as

Dr. Noor Talal AL Bdour, Assistant professor, Special education department/ Faculty of Education, Al Hussein bin Talal University, Jordan.

Dr. Fasial Mohammad AL Shogirat, Assistant professor, Law department/ Faculty of Law/ Al Hussein bin Talal University, Jordan. a complicated and embarrassing issue in the light of special factors related either to the disabled man as low income, refusal to marry by society, multiple costs and requirements of marriage, or for disabled women which is more difficult and too rare to accept their marriage, despite many of disabled women obsessed ability to have children and carry out family responsibilities.

Marriage issue of persons with disabilities also depends on several variables, such as sex, age, disability type, disability degree, economic and social status, and engagement to individual who does not suffer from disability or with an individual with the same disability or other disability, and their marriage conditions and legal awareness.

Thus, the current study attempts to review the theoretical literature and legal opinion on marriage of disabled person among agreed and disagreed teams according to different variables.

\section{II.THE FIRST TOPIC: WHO ARE PERSONS WITH DISABILITIES?}

Disability is a phenomenon known to all human societies. It occurs in varying degrees, in every place and time. It knows no boundaries and does not distinguish between people depending on their race, socio-economic class or level of culture. (Khateeb et al., 2018). Undoubtedly there is no Specific and clear definition agreed by everyone on disability, World Health organization for example defined disability "as every handicap suffered by individual as a result of an organic, physical or intellectual illness leading to a disability that enables him performing his basic duties and continue his work at the normal rate", The Jordanian Persons with Disabilities Law No. (31) specifies person with disabilities as: "everyone has a complete or partial disability in any of his or her physical, intellectual or sensual abilities to the extent that limits the possibility of learning, rehabilitation or work, so he cannot meet the requirements of his normal life like other nondisabled persons".

Thus, Disability is the inability to complete perform one or more important activities as a result of injury of a basic function. Some researchers have pointed out that disability is a social and cultural stigma, which the owners attempt to conceal, but its existence makes them weak in their interaction with others, and may lead to a total or partial withdrawal from many social relations, including marriage, and put disabled and their families in an inappropriate and abnormal situation. (Al-Khatatna, 2000), noticeably Individuals with debilities 
categories are classified as: intellectual disability, learning disabilities, physical and health disabilities, hearing impairment, visual handicap, behavioral and emotional disorders, communication disorders, and autism (Bdour et al., 2019).

\section{THE SECOND TOPIC: PERSPECTIVES ON MARRIAGE OF PERSONS WITH DISABILITIES}

Persons with disabilities marriage is one of the most rights guaranteed by the International Convention for Persons with Disabilities Rights, which was signed and ratified by Jordan in 2007, most important is which stated in Article (23): "Persons with disabilities of age of marriage shall have the right to marry, form family, with full consent and no compulsion (The higher Council for Persons with Disabilities, 2007).

Marriage of disabled persons issue varies according to the nature of each case and its specificity, and varies according to different variables such as type of disability (intellectual, auditory, visual, physical, emotional, communication, autism, etc.), sex (male or female), casual factor as a result of heredity or chronic illness, and so on (Shaban, 2008).

In general, different studies discussed attitudes towards marriage of disabled person, Abo Mosa for example indicated on marital compatibility topic and its relation with shyness features for disabled person, results showed that there was no correlation between marital compatibility and shyness among disabled according to several variables such as sex, age, type of disability, duration of marriage and scientific qualification.

Al-Dodi (2009) discussed the problems and challenges faced by the families of disabled individuals through a study of (308) parents of disabled children to know the nature of psychological stress and its relationship with marital and family compatibility compared to (340) parents of ordinary children, found that marriage is affected by the degree of disabilities, more severe the disability more problems faced by the family.

Al-Jazmawi (2016) dealt with the great social, psychological and economic problems faced by wives of disabled person in Tulkarm governorate, as hard economic conditions, low incomes, high unemployment and desire of many women to escape from life difficulties and psychological and familial pressures. AL Jafra, 2016 conducted the attitudes of families with disabilities about the marriage of their disabled children and its relationship with the quality of life. These attitudes were negative, with an inverse relationship between attitudes of families towards the marriage of their children with disabilities and the quality of life, especially in the family and social dimension.

With regard to the attitudes towards persons with intellectual disabilities marriage, especially the mild type, according to different variables such as age, gender and disability; Saeed (2009) notes that marriage of persons with disabilities is generally guaranteed to individuals with mild intellectual disability in a particular way, two points of view divided as:
1- Support marriage of persons with disabilities such as any person who has no disability.

2- Refusal marriage of persons with disabilities because it increases the burden of society and is condensate to failure.

Many studies have examined the marriage of persons with intellectual disabilities according to different variables. Flannery, 2004 discussed issues about marriage and sexuality by looking at the traditional teachings of Roman Catholic as marriage is the basis for the existence of sexual activity and the judgment of the nature of relationships, he stressed right of the intellectually disabled to marry and engage in sexual activity which commensurate with human nature.

O' Callagan \& Murphy, 2007, addressed the subject of sexual relations for intellectual disabled adults with average of age (37.5), especially their understanding for marriage law, they found that disabled had very limited knowledge of laws related to sexual relations such as consent, conditions of marriage and penalty for sexual exploitation, and protection afforded to them by law. Saeed, 2009 in Palestine dealt with the attitudes of young men and women towards marriage of the intellectual disabled at sample of 100 individuals. A high percentage of those who believe that religion does not allow marriage of $=$ disabled, government don't support their marriage, many ordinary people thought that intellectual disabled persons are unable to take responsibility of marriage and more than $88 \%$ are not willing to marry from intellectual handicapped persons.

In regards of families, Aljamahouni, 2015 studied the attitudes of mothers towards the marriage of their intellectually disabled children in Saudi Arabia, found that there were no statistically significant differences in positive mothers attitudes by sex ( male or female) while they differed according to location in favor of the city on the Badia and on higher educational, economic and social level.

In Jordan, Tarwaneh and Al-Ataiwi,2017 examined attitudes of Jordanian people towards the marriage of persons with mild intellectual disabilities, the percentage of those who rejected marriage of persons with disabilities was 50.9 with a statistically significant differences according to age variable, and there are no differences according to other variables such as gender and Educational Qualification.

In terms of other disabilities, such as sensory as visual and hearing impairment, physical handicap we found that few studies shed light about marriage of disabled persons with different variables. Regarding the subject of sexual education for their disabled children, Jameel (2001) noted that there are statistically significant differences between average scores of parent's attitudes towards marriage of the disabled in favor of children with hearing and visual impairment on the children with intellectual disabilities (Aljamjamouni, 2015).

Mc Conkey, 2011, conducted a study of Irish attitudes on sexual relations of individuals with disabilities. Results showed that half of the study population believed that people with intellectual disabilities and autism had the right to marry, One-third of study sample believed that they should have 
children if they wanted to. Many agreed that Individuals with physical or sensory disabilities have the right to have sexual relations and have children more than people with intellectual disabilities. The consent of individuals right to marry disabled persons has increased in the existence of important conditions such as: living outside Dublin, his knowledge about the desired goals of marriage, single status, psychologically and economically stable.

\section{THE THIRD TOPIC: THE LEGAL OPINION ON MARRIAGE OF PEOPLE WITH DISABILITIES}

Marriage is one of the rights guaranteed by the Constitution and the laws. As a basic component of society, the law does not prohibit marriage of disabled person and living in family environment, the Jordanian Constitution has protected rights of persons with disabilities from all aspects (Article 5) of the Jordanian Constitution, specifically Paragraph (1) of the same article equals between Jordanians and did not deprive persons with disabilities to enjoy on their rights, marriage issue was organized in Jordan in general in Personal Status Law, as a contract between a man and a woman in legal form to constitute a family, this law stipulates eligibility of person to marry, which is 18 years of age and completion of -mental force (the Jordanian Personal Status Law).

However, this law provided a special provision concerning marriage of persons with disabilities in Jordan, which gives judge the right to marry a person with madness, dementia, or intellectual disability, provided that his benefit from marriage according to a formal medical report, improve that infection is not transmitted as a result of the marriage to his offspring, he is not a danger to his wife and to obtain the consent of this partner (the Jordanian Personal Status Law), we find that the provisions of law are very important and that the legislator is successful in approving these provisions, for what it was offered of benefits for both parties of marriage contract and their families, and ability of dealing with family life which is not without responsibilities and troubles.

In addition to above, Jordan Rights of Persons with Disabilities Law guarantees that rights of persons with disabilities, including marriage and respect for social life, and not to be deprived of enjoyment of various rights and freedoms he obtains. The Ministries of Social Development and Health have committed themselves to enhancing the living skills and self-reliance and developing their rehabilitation programs, as well as directing all concerned to promote culture of acceptance persons with disabilities as part of human diversity (Law of the Rights of Persons with Disabilities), not even law has imposed legal sanctions on anyone who delays or exceeds the rights granted by the law to persons with disabilities, including marriage, law decided to form councils and committees that deal with persons with disabilities and their rights and follow up their affairs, We would like to thank legislator for taking this step.

\section{CONCLUSION}

Disability is a social and cultural stigma and often leads to a total or partial withdrawal from many social relationships including marriage which places disabled and their families in an inappropriate and abnormal position. By reviewing the views and attitudes towards marriage of disabled Persons we found it generally negative, with an inverse relationship between attitudes of families towards marriage of their children with disabilities and quality of life, especially in family and social dimension. According to the type of disability, attitudes towards marriage of persons with intellectual disabilities, especially the mild type were divided into two parts; supported and non- supported despite the right of the intellectually disabled to marry, have sexual activity and having children which Commensurate the human nature.

Few studies have highlighted issue of marriage of persons with sensory, visual and physical disabilities, but some of them have supported their right to have sexual relations and have children more than people with intellectual disabilities. The Jordanian law provides a special provision concerning marriage of persons with disabilities, which gives judge the possibility to marry madness, dementia, or intellectual disability, provided that his benefit from marriage according to a formal medical report and other conditions. The Jordanian Law on Rights of Persons with Disabilities has also committed to rights of persons with disabilities, including marriage, and imposition a legal sanction on anyone who delays or exceeds their rights.

Finally, study recommends conducting more studies on disabled persons marriage, especially visual, hearing and physical disability, take more procedures to facilitate the marriage of persons with disabilities and follow-up imposing legal sanctions on anyone who violates this right.

\section{REFERENCES}

[1] - Abu Musa, Sumaya Mohammed (2008). Marital compatibility and its relation to some personality traits of the disabled, unpublished master thesis, Islamic University, Palestine.

[2] - Al-Attawi, Walaa and AL Tarwaneh, Rodina. (2017). Attitudes of the Jordanian people towards the marriage of persons with simple intellectual disabilities and the effect of some variables on them (a comparative descriptive study). Tishreen University Journal for Research and Scientific Studies, vol. 39, No. 1, pp. 99-119.

[3] - Al-Bdour, Nour; Nawafla, Hani and Nasrat, Mohammad (2019). A survey study of Demographic and Social Characteristics of Persons with Disabilities in Petra / Jordan. Jordanian Journal of Social Sciences, Volume 12, Issue 1, p.p: $103-118$.

[4] - Al-Dodi. Ghazlan, Shamsi (2009). Psychological stress and marital compatibility in a sample of parents of disabled individuals according to type and degree of disability and some demographic and social variables, unpublished master thesis, Um Al Qura University, Saudi Arabia.

[5] - Al-Jafra, Sharifa (2016). The attitudes of families with disabilities towards the marriage of their children and their relation to the quality of life, unpublished master's thesis, Mutah University, Jordan.

[6] - Al-jamahouni, Amal Mohamed, (2015). The attitudes of mothers towards the marriage of their children with intellectual disabilities in the province of Anza in Saudi Arabia, Journal of Environment Behavior, Volume 3, Issue 2, pages 222-250. 
[7] Al - Jazmawi, Samira Mustafa. (2016). Problems of Disabled Wives in Tulkarm Governorate, Master Thesis, An-Najah National University, Palestine.

[8] - Al-khatatna, Abdul Khaliq (2000). The Effects of Disabilities on the Families of Persons with Disabilities - A survey Study of Some Families of the Disabled in Irbid Governorate, Journal of Human Sciences, No. $14,27-44$.

[9] - Al-Khateeb, Jamal, Smadi, Jameel, Al-Rousan, Farouk, Hadidi, Mona, Yahya, Khawla, Al-Natour, Mayada, Zureiqat, Ibrahim, Amayra, Musa, Sror , Nadia (2018). Introduction in education of students with special needs. 8th Edition, Dar Al Fikr for Publishing and Distribution, Amman, Jordan.

[10] - Flannery, Kevin, (2004). Marriage, intellectual handicap and sexuality, SAGE Publication, London. pp 11-26. https://doi.org/10.1177/095394680401700302

[11] - Mc Conkey, Roy. (2013). Irish attitudes to sexual relationship and people with intellectual disability, British journal of learning disabilities, vol. 14, pp. 181-188. https://doi.org/10.1111/bld.12036

[12] - O' Callaghan A.C \& Murphy. G.H. ( 2007). Sexual relationships in adults with intellectual disabilities: Understanding the law, Journal of intellectual disability research, vol.51, part3, pp. 197-206. https://doi.org/10.1111/j.1365-2788.2006.00857.x

[13] - Saeed, Maram (2009). Marriage of the intellectually disabled in the Palestinian community of Jerusalem, the Palestinian Center for Guidance. http://www.broonzyah.net/vb/t200227.htlm

[14] - Sufian, Bushra (2008). The marriage of the disabled from legal, medical and psychology points of view. Al-Anbaa journal, Kuwait

[15] - Jordanian Persons with Disabilities Law No. 31 of 2007, higher Council for the Affairs of Persons with Disabilities, Amman, Jordan.

[16] - Articles $(4,5,29$ and 41) of the Law on the Rights of Persons with Disabilities No. 20 of 2017.

[17] Article (6) paragraph (5) of the Jordanian Constitution. -

[18] - Article (10) paragraph (A) of the Jordanian Personal Status Law.

[19] - Article (12) of the Jordanian Personal Status Law 